\title{
Accès au tunnel sous la Manche (Terminal Transmanche)
}

\section{(apenEdition}

Journals

Édition électronique

URL : http://journals.openedition.org/adlfi/10085

ISSN : 2114-0502

Éditeur

Ministère de la culture

Référence électronique

"Accès au tunnel sous la Manche (Terminal Transmanche) », ADLFI. Archéologie de la France-

Informations [En ligne], Nord-Pas-de-Calais, mis en ligne le 01 mars 1997, consulté le 20 avril 2019.

URL : http://journals.openedition.org/adlfi/10085

Ce document a été généré automatiquement le 20 avril 2019

(C) Ministère de la Culture et de la Communication, CNRS 


\section{Accès au tunnel sous la Manche (Terminal Transmanche)}

1 Parallèlement aux travaux de construction du tunnel sous la Manche, l'emprise du chantier situé du côté français (Fig. $n^{\circ} 1$ : Localisation des zones fouillées) a fait l'objet (1986-1988) de prospections de surface, de sondages puis de fouilles de sauvetage sur les secteurs les plus sensibles.

2 De par son ampleur (plus de $900 \mathrm{ha}$ ) et le caractère systématisé du traitement archéologique,cette opération reste une référence de première importance au plan régional, mais aussi national. Elle préfigure les recherches de même type menées dans les années suivantes sur les grands projets d'aménagement (TGV Nord, autoroutes, etc.). Si cette intervention n'a pas bénéficié des mêmes moyens matériels que les opérations de diagnostic archéologique les plus récentes, les résultats acquis sur les vingt-et-un secteurs fouillés n'en sont pas moins importants et concernent des époques aussi diverses que le Paléolithique ou le Bas Moyen Âge. Près d'une trentaine d'archéologues sont intervenus sur les différents sites.

3 Au terme de ces fouilles, menées aussi bien par le Service régional de l'Archéologie de la région Nord - Pas-de-Calais que par l'Association pour les fouilles archéologiques nationales (AFAN), ce sont près de 10 ha qui ont été entièrement décapés. Ils ont livré des centaines de structures et des milliers d'objets, silex taillés, céramiques, ossements, mobilier métallique, tous inventoriés et préservés. En parallèle, ce sont également des centaines de plans et de relevés mais aussi de clichés photographiques qui ont été réalisés.

4 Presque toutes les périodes préhistoriques, protohistoriques et historiques sont représentées sur les chantiers du Transmanche, mais les résultats les plus marquants concernent les époques suivantes :

5 - Âge du Bronze (2000 à 800 avant J.-C.) : deux nécropoles à grands enclos circulaires, Fréthun « les Rietz » (site L) et Coquelles « RN1 » (site G);

6 - début du second Âge du Fer (époque gauloise, 450 à 250 avant J.-C.) nombreuse traces d'habitat sur divers sites ; 
7 - période gallo-romaine : la villa de Fréthun « les Acqus des Alleux» (site 0 ) et les tombes à incinération de Coquelles « la Route » (site K);

- Haut Moyen Âge : nécropole mérovingienne de Fréthun «les Rietz » (site L), ainsi que la motte, l'église et le cimetière de Fréthun « la Carrière des Morts » (site $Q$ ) ;

9 - Bas Moyen Âge: le village de Sangatte «les Terres Genées» (site U) et les fermes de Coquelles «la Grande Rouge Cambre » (sites C et J).

10 Tous ces éléments permettent de retracer les grandes étapes de l'évolution de ce terroir du Calaisis et représentent un apport majeur pour la connaissance de l'histoire de cette partie du littoral, peu de sites de cette importance ayant été fouillés depuis.

\section{ANNEXES}

Fig. $\mathrm{n}^{\circ} 1$ : Localisation des zones fouillées

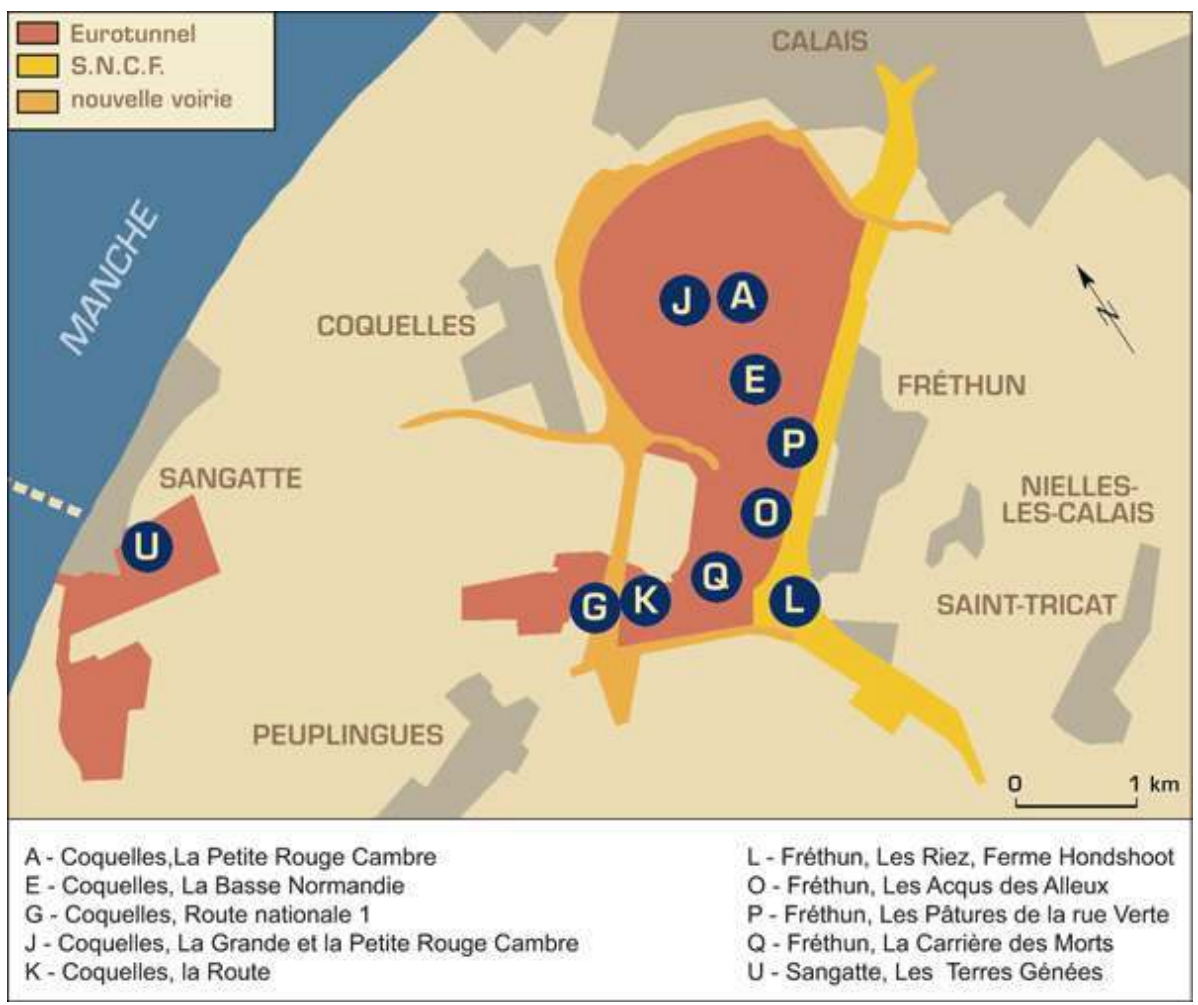

GI, 1997 - CNRS Editions, 1998 (1997) 
INDEX

Index géographique : Nord-Pas-de-Calais, Pas-de-Calais (62), Coquelles, Fréthun, Sangatte Index chronologique : âge du Bronze, âge du Fer, Antiquité romaine, bas Moyen Âge, ép. mérovingienne 